View Article Online / Journal Homepage / Table of Contents for this issue

\title{
PRESIDENTIAL ADDRESS.
}

Delivered at the Annual Generai Meeting, Marci 22 nd, 1907.

By Raphael Meldola, F.R.S.

\section{The Position and Prospects of Chemical Research in Great Britain.}

The Status of Original Research.

I HAVE taken for the subject of this year's address a theme which appeals to us all in various ways, and which I propose to discuss under the above heading. According to our Charter we exist as a Society "for the general advancement of Chemical Science." This is tantamount to a declaration that our primary object is the promotion of original research because, although there are many ways of promoting a science, original investigation is unquestionably the most important. Our publications bear testimony to the fact that our Society has well carried out and is still actively promoting the object for which it was founded sixty-six years ago. A critical examination of our publications will further show that the output of original work is, on the whole, increasing both in quality and in quantity. In order to bring out this point our Assistant Secretary, Mr. Carr, has at my request compiled a table dealing with the period from 1895 to 1906 inclusive, and giving under different columns the number of papers contributed to the Transactions and Proceedings, the number of contributing authors, and other useful information. The table itself may be consulted for details, ${ }^{*}$ but just to give an idea of the rate of progress I may state that, in 1895,109 authors contributed 116 papers to the Transactions and 132 authors contributed 157 abstracts or papers to the Proceedings. In 1906, 183 authors contributed 186 papers to the Transactions and 215 authors contributed 236 abstracts or papers to the Proceedings.

It is impossible to contemplate these figures without coming to the conclusion that a generation of active workers is springing up of which we have every reason to be proud, and in whose keeping we, whose period of activity cannot in the order of nature last very many years, may feel assured that the reputation of our Society will be honourably maintained. Taking advantage of my present position for addressing this newer band of workers, I would ven-

\footnotetext{
* See Appendix A, p. 659 ,
} 
ture to point out that the investigations which you are carrying on are of an importance which perhaps even the greatest enthusiasts in your ranks have hardly yet realised. It is not alone the individual discoveries, it is not only your personal contributions to the great edifice of human knowledge, neither is it the practical applications of your discoveries that constitute the supreme importance of this work, the results of which you are giving to the world. We are all labourers in a common cause-the maintenance of the spirit of scientific research-and it is to organisations like this and kindred societies that we look for the preservation and perpetuation of that spirit. Every advance made into the limitless regions of the unknown, whether by a few humble steps or by the flying leap of a great generalisation, must be regarded as a contribution to the common cause. We must take a broad, an imperial view of original research if we desire, as we all do, to influence the public mind. Every discovery emanating from your laboratories not only helps to extend the boundaries of our science but it helps also to uphold the general principle that original research is in itself and by itself the most powerful weapon that has been or ever can be wielded by mankind in struggling with the great problems which nature offers on all sides for solution.

It may appear superfluous for me to sound a pæan on behalf of original research before the Fellows of a Society which ostensibly exists for the very purpose of promoting research. It is, however, unfortunately only too notorious that in this country the general public attitude towards research is either apathetic or else narrowly practical-narrow to the extent of crippling real progress. Although we may all, individually and collectively, realise the importance of our mission, the nation as a whole cannot be said to have given recognition to the principle that the productive activity of the scientific worker is one of the prime factors concerned in all national development, and that the credit of the country in the eyes of the civilised world demands that our rate of progress in the field of scientific discovery should go on increasing from generation to generation. It may be useful, therefore, to take advantage of opportunities such as this to remind the outer world from time to time that in this and in our sister societies, both within and without the presincts of Burlington House, there exist bands of ardent workers who are fighting in this great cause, often in face of adverse influences arising directly or indirectly from public indifference or other causes, some of which I propose dealing with in this address.

To all who are familiar with the influence of scientific progress on the evolution of civilisation, that is, to all students of the his- 
tory of modern science, the general want of appreciation of research here cannot but be a matter of profound wonderment. It is not my intention to attempt an analysis of the causes of this public apathy on the present occasion. We must, I am afraid, deal with it as an accepted fact. Attention has from time to time been called to this national weakness by the Press and by publicists whose influence should carry conviction to the lay mind. We can, no doubt, remember weighty utterances by statesmen such as the Duke of Devonshire, the late Lord Salisbury, Lord Rosebery, Mr. Chamberlain, Mr. Balfour, and, above all, in recent times, Mr. Haldane, who loses no opportunity of driving home the lesson of the importance of science and of scientific method to the national welfare. Nor have our scientific workers themselves failed to sound the note of alarm with all the authority of expert knowledge. But, in spite of these individual efforts, it cannot be said that we have made much headway; public interest in scientific research may still be considered to be on a low levelcertainly lower here than in many other leading nations, and most decidedly lower than is desirable in the best interests of our country. A temporary flicker of excitement is caused when some sensational discovery is announced, or when some result of immediate practical (commercial) value is made known, but even in these cases the interest taken is only transitory and is narrowed down to the immediate issue; the broad cause which makes such results possible is lost sight of. The steady, plodding work which culminates in great discoveries is being carried on quite unheeded by the general public, and the workers themselves are practically unknown outside the ranks of science. Research as a "cult" is not understood; the national attitude towards the workers is one of "payment by results" in the very narrowest sense of the term.

How this state of affairs is to be remedied is a knotty question which I confess appears to me somewhat hopeless of solution at the present time. It may be that by persistent attack from within and the pressure of competition from without the country will, in fact must sooner or later, awaken to the situation. It may be that science will have to become more self-assertive and make its influence felt as a political power. There is need here, as has been often suggested, for a Minister corresponding to the "Minister of Public Instruction," or the "Cultus-Minister" of other countries. The newly-formed "British Science Guild" may fairly be expected in the course of time to help us in raising the level of public opinion towards the importance of research, this being, in fact, one of the primary objects for which this organisation has been founded. It is safe to assert that any individual 
or organised body of workers, however zealous, who undertake this mission will have a Herculean task to perform. But, in the meantime, while waiting for the era of public enlightenment, there must be no pause in your search for new knowledge; there is no need to call a halt; there are boundless "regions yet untrod" awaiting your enterprise. The imperial view of research which I am advocating will add zest to your labours if you consider that by your individual efforts you are helping forward the general cause which we all have at heart. The new recruits which our little army of research chemists has gathered into its ranks are missionaries in this cause and active witnesses to the truth of the doctrine that the creativeness of its scientific men is one of the most precious assets which the country possesses. It is perhaps unnecessary to qualify this statement with the caution that I am not advocating a policy of bluster or of exaggerated self-assertiveness towards the non-scientific laity, or the equally objectionable policy of constituting ourselves a mutual admiration society. The temperament of our countrymen may, happily, be depended upon for keeping them clear of the danger of assuming an attitude which is both derogatory to science and damaging to its status in the public estimation. At the same time, it is impossible to survey the achievements of our little army of workers during the last decade without coming to the conclusion that neither in zeal or originality, nor in any of the qualifications which have enabled other nations to advance the cause of chemical science, are we lacking in this country.

\section{The Jubilee of the Foundation of the Coal-tar Colour INDUSTRY AND ITS LESSONS.}

The exaltation of scientific research into an abstract principle or "cult," which is the keynote of the remarks which $I$ have put together for your consideration on this last opportunity when I shall have the honour of addressing you from the Presidential Chair, is, of course, a familiar subject to all who keep in view the objects of a society such as this. If I venture to formulate the principle somewhat more emphatically on this occasion, it is that the international gathering, which took place here last summer in honour of our distinguished past-President, Sir William Perkin, and in celebration of the jubilee of the foundation of the coal-tar colour industry, has given rise to many considerations which are intimately associated with the subject of this address. Although at that memorable assembly the voice of the nations was raised in gratitude for and in recognition of the numerous benefits aris- 
ing from the establishment of a great industry, we must not forget that below the chorus of praise and congratulation, so justly sounded in honour of the founder, there was flowing an undercurrent of thought which, in some of the addresses and speeches, found verbal expression-the thought that this industry owed its existence to scientific research, and that it had been developed into its present magnitude by the never-ceasing applications of research. Certainly, Perkin himself has never lost an opportunity of driving home this lesson either to his scientific colleagues or to the general public. I have no desire to exalt the coal-tar industry into a position of undue prominence, although $I$ have myself served an apprenticeship thereto, but it is now quite notorious that no branch of modern industry has ever furnished such a striking object-lesson in the application of scientific research to industrial progress.

I confess that there was sore temptation in sketching the outlines of this address to take advantage of last year's jubilee, in order to treat specifically of the history of the coal-tar industry from the point of view of the bearing of pure scientific discovery upon its progress and development. It is thought by many who are acquainted with this chapter in the history of chemistry that there is still scope for such a thesis. On the present occasion, however, it is perhaps better to avoid handling a topic which must necessarily be more or less technical, especially in view of the fact that this aspect of the subject has already been dealt with to some extent by chemists, many of whom are well qualified to speak with expert authority. It is only necessary to remind you of the addresses delivered before the German Chemical Society in 1890 in honour of Kekulé, on the occasion of the celebration of the foundation of the benzene theory; of the Griess obituary notices by Hofmann, Emil Fischer, and Caro, published by the same Society in 1891; of Caro's well-known lecture on the industry, delivered before the German Chemical Society in 1892; of the Hofmann memorial lectures, delivered before this Society in 1896 by Lord Playfair, Sir F. Abel, Dr. Perkin, and Dr. Armstrong; and of the recent lecture by A. v. Baeyer, given in honour of the Perkin jubilee. Speaking generally, it may be said that all the great steps, the new departures in the industry of coal-tar products, have been the outcome of pioneering work carried on in the first place without immediate reference to practical results. All honour to those who have developed these results into manufacturing operations, but honour in the first place to the scientific pioneers! This is the real lesson taught by the celebrations of last July. It may be of interest to consider in the next place 
how far this lesson has been learnt here on the one hand by the scientific public and on the other by the general public.

That the lesson has not been learnt by those who are most immediately concerned, the manufacturers themselves, is sufficiently apparent when we compare the enormous development of the industry in Germany with its comparatively small development here and its decadence in France, once an active centre and a successful competitor with us in the manufacture of coal-tar colouring-matters. This, I am fully aware, is a sore topic with our manufacturers; but, unfortunately, the facts are only too obvious. A recent paper by Dr. James T. Conroy on "The Chemical Trade of England and Germany-a Comparison" (J. Soc. Chem. Ind., $1906,25,1011)$ will be found very instructive by those who require later statistical details. With respect to the public attitude, it may be said that such appreciation of Perkin's work as was expressed through our Press was just what might have been anticipated in a country where the true position of scientific research is imperfectly understood. The rejoicing was over the purely practical achievement-the discovery of the convertibility by chemical processes of so many otherwise useless tar products into saleable articles of commerce. The public cannot, as matters now exist in this country, go behind such proximate results. Moreover, the limitation of the appreciation in this way brings out very clearly the difficulties which must be ercountered in any attempt to raise the status of scientific research in general, and of chemical research in particular, in the national estimation. Consider, by way of contrast, the works of the litterateur or artist; these appeal directly to the public or to some section of the public, and can be appreciated according to their merits. Not so the labours one scientific investigator; his achievements are measured solely by the utilitarian standard; he is, as I said before, paid strictly by results. In other words, while Literature and Art have taken their position as "cults" in all civilised nations-a position to which they are fully entitled-Science is judged by a lower and narrower standard, and certainly cannot be said to occupy in this country the same position as its sister branches of culture.

With respect to our own branch of science, Chemistry, it may be especially said that it is not generally recognised that the socalled "practical" achievements are few and far between; that they do not spring already perfected from the fertile brain of some "inventor," but are always led up to by numerous discoveries which, according to the national standard of valuation, would be considered worthless. The jubilee celebration of last summer is particularly instructive from this point of view. I do not think 
that it was at all realised by the public that the rejoicing on that occasion was over something more than the discovery of mauve and the foundation of a new industry. Those representatives of our science who were present could have told the nation that the founder of that industry had half a century ago vindicated the claims of pure scientific research to take rank as a real power spelling prosperity in the hands of those who have learnt the lesson of how to use it. They could have told the public also that while the accidental discovery of mauve in the course of a scientific attempt to synthesise quinine was not in itself a very remarkable achievement, that chance observation happened to be made by a young man who was prompted to try the experiment by legitimate deduction, and who was so imbued with the spirit of research that he followed up the hint thus given with true scientific method and developed a laboratory preparation into a factory product involving the use of raw materials which had never before been made on the large scale, and which had been discovered by previous generations of chemists who could never have dreamt that their results would be raised to the importance of being of "practical" use. So, also, it could have been pointed out that while Perkin himself never manufactured more than some half a dozen colouring-matters during his connexion with the industry, the total number now on the market being about 1,000 , he had synthesised scores of compounds, and had made other discoveries of no commercial value whatever but which are of no less importance, in fact, are really of greater scientific importance, than the half-dozen dyestuffs made at Greenford between 1856 and 1873, and which would lose none of their interest for us had mauve never been discovered and the coal-tar colour industry never called into existence. It may be said in brief that it was the principle of research that was being honoured in the person of one of the great pioneers in the application of chemical science to chemical industry, and that the gratitude expressed by the nations was not alone for the material benefits arising from the industry, but equally for the enormous impetus which the new branch of manufacture gave to the development of pure chemistry, this being a chapter in the history of our science now, of course, familiar to all students of that history, but which certainly remained unread by the outer world at the time of the gathering here last July.

Although giving special prominence to the scientific aspect of the work of our distinguished colleague, I am most anxious to avoid the imputation that $I$ am depreciating the industrial side of his particular achievements or the application of chemical 
science to industry in general. My contention is for the principle that scientific research, like every other branch of human culture, is worthy of national homage, whether it leads to immediately "practical" results or not-that its position in the scale of civilising agencies is not dependent upon such occasional stimulants as the jubilee of the foundation of a new industry or the announcement of a sensational discovery which furnishes materials for newspaper paragraphs. It would, I think, be generally admitted that any country which limited its appreciation of research to such branches of science as were likely to lead to industrial developments was on a low level in the scale of civilisation. It happensperhaps I may add fortunately for us - that our particular science has its utilitarian side, but that is, so to say, a happy accident which has in many ways promoted our cause. I may remind you that in our Charter a kind of utilitarian excuse had to be found for granting the privilege of incorporation to the original body of members, that excuse being that Chemical Science is "intimately connected with the prosperity of the manufactures of the United Kingdom, many of which mainly depend on the application of chemical principles and discoveries for their beneficial development," and that the Chemical Society had further for its object "a more extended and economical application of the industrial resources and sanitary condition of the community." But, as you all know, the enormous development of our subject has necessitated the formation of other societies dealing with the industrial and professional sides of chemistry, and although we have now limited our work to the primary object, "the general advancement of Chemical Science," the Fellows of this parent Society are none the less cognisant and appreciative of the activity and efficiency of those other organisations to which we have given rise in the course of our history.

In maintaining the principle that scientific research has been, is being, and can always be carried on independently of its practical applications, I have no desire to give countenance to the view, somewhat prevalent, I fear, in this country, that there is some kind of antagonism between pure and applied science; that the scientifically trained chemist, for example, and the "practical" man, instead of being allies, as they should be, are in opposition. The days when such notions were held are, happily, passing away; if but slowly in this country much more rapidly abroad. My plea simply amounts to a claim for the readjustment of the positions of pure and applied science in the public estimation. The course of industrial development in the future is bound to become more and more interwoven with the development of pure science, and 
the perpetuation of erroneous ideas on this point cannot but act injuriously on both causes. In our own domain it is absurd to suppose that there is any antagonism between the two aspects of chemistry. Far from this being the case, it may safely be asserted from the experience furnished by the coal-tar industry that the rate of progress is actually measurable by the degree of substitution of pure science for empiricism. Those manufacturers who fail to recognise this principle do so at their own peril; those who have realised its truth cannot but admit that the more enlightened views respecting the function of science in the factory have been largely due to the influence of Perkin's work and example half a century ago.

\section{Chemical Research in Educational and Manufacturing Centreis.}

Having thus attempted to give expression to the views of chemists concerning the position of research, I will, in the next place, venture to submit the question whether the output of work, to which attention was called in the early part of this address, is really representative of the productive capacity of the nation, and, if not, whether there are retarding or deterrent causes in operation tending to check the progress of chemical research in this country. In dealing with this part of the subject, a few preliminary considerations must be made clear. In the first place, although we comprise within our ranks practically all the active workers, we cannot lay claim to be the only publishers of original chemical research in Great Britain. Some distinguished authors, as we know, have contributed their papers to the Royal Society, the Royal Society of Edinburgh, the Royal Irish Academy, the Cambridge Philosophical Society, the Manchester Literary and Philosophical Society, and other publishing bodies, or have published directly through some scientific magazine or journal. Our workers occasionally also send their results to the German Chemical Society for publication in the Berichte or to the French Academy for publication in the Comptes rendus. I have taken the trouble to look into the question of the publication of chemical papers by British chemists through channels other than our Transactions and Proceedings, and have come to the conclusion that such an overwhelmingly large proportion of the work done is communicated to our Society that we may justly claim that our publications are fairly representative of the total activity of the country in the way of research. I will remind you further that such papers as do appear in our pages have, as it were, received 
the stamp of originality or fitness for insertion in our journal by being filtered through the Publication Committee, and I think we may legitimately claim also that the standard of quality thus insured has, on the whole, been maintained at a high level. In the next place I would urge that, as we have in the past fulfilled and are now carrying out that primary object for which the Society was founded, it is our solemn duty to look upon ourselves as the custodians of chemical research in this country, and that we are bound, at least morally, if not by virtue of any executive powers, to safeguard and look after the interests of research whenever and wherever it may be carried on, and to take cognisance of any deterrent causes that tend to hamper its progress. In giving publicity to the opinion that there are many such antagonistic influences in operation here, I am not in the smallest degree attempting to minimise the value of the work which is being done. On the contrary, when we consider what has been and is being accomplished in the face of serious obstacles, and often at the cost of great personal sacrifice, the value of the achievements becomes enormously enhanced and the sterling quality of our workers is brought more vividly into prominence. The question actually before us is whether we are getting as much in the way of original investigation as might fairly be expected in view of the potential research talent known to exist in our ranks. If, as I maintain, this is far from being the case, it may be at least useful, even if no definite remedial measure can be enforced, to examine into and make known publicly the causes leading to this suppression of talent. It is confessedly a very large subject to deal with adequately in the course of an address, and the task is by no means lightened by the reflection that however strong a case can be made out in support of the conclusions at which we may arrive, we have no power in our corporate capacity to insure compulsory action for the amelioration of the present state of affairs. We are not in the position of a church militant, declaring a crusade against scientific unbelievers, neither can we exert the influence of a trades union and proclaim a strike among our workers. All that we can do is to direct attention to the retarding influences in the hope that a public expression of chemical opinion may lead to some improvement in the existing conditions.

In dealing with the question under consideration, the first point to which attention must be directed is the character of the institutions in which research is being or might be expected to be carried on. We may begin with such establishments as those which have been built and endowed, and are being maintained for the specific purpose of enabling research to be conducted under 
favourable conditions, like the Royal Institution and the DavyFaraday Laboratory, founded by Dr. Ludwig Mond. Then, also, there are certain public establishments like the Royal College of Science, the Central Technical College, maintained by the City and Guilds of London Institute, University College, London, the Government Laboratory, the Imperial Institute, the Pharmaceutical Society, and the Research Department at Woolwich, which, although not primarily founded for the prosecution of abstract research only, have helped to enrich our science by the publication of results obtained in their laboratories. To these may be added certain semi-private establishments, founded in connexion with particular industries, such as the Lawes Agricultural Station, to which the Goldsmiths' Company has recently made the munificent grant of $£ 10,000$, the Wellcome Research Laboratories, and the Guinness Research Laboratory. The Lister Institute also must be regarded as a contributing laboratory. To all these centres of research our science is indebted for many notable advances, and beyond expressing our gratitude to the founders, supporters, and workers in the various laboratories, I have nothing to do with these institutions excepting perhaps to point out that many of them are most inadequately endowed and supported, in view of the national importance of the work which they enable our active chemists to carry out.

After giving to these institutions and establishments all the credit to which they are justly entitled, there remain two other groups of centres in which research might be expected to flourish. I refer to educational establishments and to factories. With respect to the latter, it may be said that any research which is conducted in their laboratories is for trade purposes, and that they could not reasonably be expected to give publicity to the results. This is a perfectly fair contention as far as it goes, and the consideration of factories as centres of research might very well have been regarded as beyond the province of this Society. I should not have ventured to touch upon this point here were it not that it is in reality most intimately bound up with the other aspect of the subject under consideration, viz., the part played by educational establishments in furthering chemical research in this country. This connexion will, I hope, be made clear in the course of the subsequent remarks.

Turning to educational centres, we have in the first place the Universities, University Colleges, and Institutions of University rank. A few of these, such, for example, as the Victoria University at Manchester, where a recognised school of chemistry has been created, and Cambridge, whence contributions of importance reach 
us from time to time, are doing good service in the cause of chemical research, as witnessed by the pages of our publications. From other University laboratories, also, we receive occasional communications, these being for the most part the work of the professors. But with the exception of Manchester, it cannot be said that in any of our Universities has there been called into existence an active centre of chemical research-a "school" in the Continental sense of the term. I do not propose dealing in detail on this occasion with the very large question of the position of research in our Universities, but putting the case broadly, we should, I think, all agree that after making allowance for the few noteworthy exceptions, the actual contributions to our science from these centres are far below the standard, both of quality and quantity, which might be expected and which we should all like to see attained. If any doubt on this point should exist, it is only necessary to call to mind the productive activity in the Continental Universities as compared with our own. Judged by this standard, there can be only one conclusion-that many of our Universities are distinct failures as centres of chemical research, and that the total output of work from University laboratories is by no means worthy of the great traditions of this country as a pioneering nation in scientific discovery. The most discouraging aspect of this conclusion is that, in spite of the enormous development of our science during the three-and-twenty years that have elapsed since the presidency of Sir William Perkin, I find myself making practically the same complaint that he made from this chair in 1884 (Trans., 45, 219). If these seats of the highest learning, called into existence for the dissemination and promotion of knowledge, can give such a comparatively poor account of their achievements in chemistry, it is evident that there must be deterrent causes at work. It would be going beyond my province to attempt a detailed analysis of these causes here; they are numerous and not easy to deal with in a limited time, but some of them are of the same nature as those affecting the position of chemical research in other educational centres which I propose discussing immediately. They may be summed up under such headings as ancient traditions, defective educational methods, want of sufficient means leading to the frittering away of the research faculty by the drudgery of " coaching," the poor outlook for chemical research as a career, and the pedantic notion that a subject requiring for its advancement something akin to manual labour is derogatory to high scholarship. Behind these causes is the general public ignorance of and apathy towards research, to which $I$ referred at the outset, and if I may paraphrase the utterances of recent authori-

VOI. XCI. 
ties in the educational world, over them all is the trail of the examining board.

In dealing with the next part of the subject, the newer educational institutions, I must crave indulgence while I invite attention to a few personal reminiscences, for it so happens that I am in the position of a connecting link between the old and the newer state of affairs in the educational world. Entering the Royal College of Chemistry, in Oxford Street, as a student in 1866, I found that Hofmann had just left this country, and I never had the advantage of coming under the direct influence of that great teacher. But the spirit of research which he had called into existence pervaded that institution, and we all know that under his inspiration a school of brilliant chemists was formed-a body of men who have left their mark upon English chemistry, both in its scientific and industrial aspects. Many of Hofmann's pupils are, happily, still with us, and it would be invidious to give a list of names; suffice it to say that many of them have occupied the chair from which I have the honour of addressing you.

At that time the prospects of a career for a scientifically trained student were not very promising. Apart from the various branches of engineering, there was no great demand for scientific men in the constructive or productive industries. Electricity had not then developed into a branch of applied science, and, although chemistry was the only science that had a direct bearing on manufactures, the number of openings in factories or in educational establishments was very limited, and the outlook for a young chemist who had to depend upon his knowledge of this subject for his living was not very hopeful. I well remember that when my own inclinations towards chemistry were under consideration, the pinnacle of success was supposed to be only attainable by becoming what was known as an "analytical chemist," a definition used to discriminate between the scientific chemist and the pharmacist, the latter, as I may remind you, having then, as now, the right to the designation "chemist." It is true that the foundation of the coaltar colour industry by Perkin in 1856 had given a great impetus to chemical training as a means of achieving industrial success, and it is well known that large numbers of students were attracted to chemistry as a career by this discovery. But by 1866 the excitement caused by the introduction of mauve and magenta and their successors had subsided, and it certainly cannot be said that the throng of zealous students who filled the laboratories in Oxford Street were altogether drawn there by prospects connected with the discovery of new colouring-matters. The influence at work in filling these laboratories was, as we have been frequently told, 
Hofmann's personality-his zeal and genius as an investigator and his brilliancy as a teacher. It was his reputation as a great explorer into the regions of the unknown that attracted many, perhaps most of us, into that Institution the destinies of which he had guided, and the one great aim of those who were launched upon their career under this inspiring influence, or under the traditional influence that long survived his departure from this country, was to find some opening in life where opportunities would be given for following the lead of the great master by contributing something towards the advancement of their science. But, as I have said, the chances of finding suitable openings were few, and it did not fall to the lot of many of us to find such opportunities. Some by stress of circumstances had to utilise their training for breadwinning purposes as soon as possible after leaving the College; others, also imbued with the spirit of research, could find no career giving scope for the development of this faculty, and were perforce compelled to expend their energies in other directions.

The state of affairs which I have outlined above persisted for many years, and in fact the conditions have not very much changed for the better down to the present time. There were but few centres of research activity in the country, and the appointments connected with these were so badly paid that other branches of more lucrative work had also to be carried on in order to make research work possible. The factories had, more or less, failed as centres for the scientific activity of trained research chemists, and the private institutions or educational establishments offered opportunities for but a very small fraction of the would-be chemical investigators. It is not surprising that in such a chilly atmosphere the spirit of research did not flourish very vigorously. A few zealous workers kept the torch alight, often at great personal sacrifice, and it is of interest to note in passing that one set of institutions from which much original work formerly proceeded, namely, the laboratories attached to some of the hospitals, have gradually declined as research centres. In view of this state of affairs with respect to the general position of research and the limited outlet for the exercise of this faculty, it will be readily understood that the new departure in modern education, which is known as the technical education movement, was hailed with most sanguine expectations by all who had at heart the scientific prestige of this country. The first step taken towards the serious development of this phase of education is due to our City and Guilds of London Institute, under which endowment evening classes were started in the Cowper Street Schools in 1879, and later a day department, which became an established part of the scheme on the opening of the Finsbury 
Technical College in 1883. The Central Technical College was opened in 1885. It is not for me to touch upon the work of our own Institute; the President of this Society is, ex-officio, a member of its Council and Executive Committee. I only refer to the foregoing dates because of the bearing of the work of the Institute on the later development of technical education. The Acts of Parliament of 1889 and 1890 placed, as you know, large sums of money at the disposal of counties and county boroughs for the purpose of furthering technical education, and there can, I think, be no doubt that the successful pioneering work of the City and Guilds of London Institute had to a very great extent prepared the way and created an atmosphere of public opinion favourable for the development of the new movement. Out of that movement there has sprung into existence a number of institutions classed here as belonging to the "Polytechnic" type, of which there are no less than twenty-three in and around London and about 110 in the provinces.

In stating that this new departure was at first regarded as a hopeful sign of the times, it is not difficult to put ourselves in the position of those chemists who were watching the course of events some twenty years ago. It was known that in ability our workers were not inferior to those of other countries; it was known that the research spirit was dormant here, but that owing to defective and obsolete methods of education and other causes this available source of national prestige and prosperity was being very largely squandered away. Here were new institutions coming into existence for the avowed purpose of improving the industries of this country; they were unfettered by ancient traditions, and ahead of them was the spirit of modern progress encouraging development along the right lines. Surely it was not unrsasonable to expect, and it was confidently anticipated by most of us, that in these laboratories there would be formed new centres of research-that the outlook for the scientifically-trained chemist would be distinctly improved. I know, as a matter of fact, that at the outset of the new movement numbers of young men of high ability and full of zeal were attracted towards these institutions by the prospect of finding themselves in a favourable environment for extending the boundaries of their science. This movement had confessedly for its primary motive the improvement of the technical skill and knowledge of scientific principles of the artisan classes, but this most praiseworthy object did not appear to be, nor is it necessarily incompatible with, the prosecution of research. So far as we are concerned, I do not imagine that many dissentient voices will be raised when $I$ state that if it was contemplated that the 
chemical industries would be improved in the same way that other industries would be advanced the movement began at the wrong end. In our particular subject it is, I think, generally recognised that the main hope of advancement is from above and not from below-that it is with the leaders and not with the rank and file that rests the prosperity of this country in the way of chemical manufactures.

If we now ask whether the modern educational development has fulfilled our expectations with respect to the advancement of chemical science, I for one must confess to a feeling of profound disappointment. There may be better times ahead when that era of public enlightenment dawns, but at present, with a few notable exceptions, these twenty-three London polytechnics are, on the whole, so little productive that we may discount them as active centres of research. It must be remembered, moreover, that this class of institution has spread all over the country, and that the total expenditure in the way of money and teaching energy is so great in comparison with the output of original work that chemists have every right to ask why this state of affairs should exist. I may remind you that only a few years ago, when the University of London was being organised, the late Sir Michael Foster published an article on the polytechnics, the main gist of which was to urge upon these institutions the necessity of developing research; if any justification for my own note of disappointment is necessary, it is to be found in the circumstance that such an appeal should have been necessary at all.

Turning now to the consideration of the causes of this failure on the part of the new educational establishments, I must, in the first place, guard myself against the imputation that I am disparaging their work. The most acute form of disappointment is that which is experienced when we find weakness where we had looked for strength, and in emphasising their weakness from our standpoint I am not shutting my eyes to their usefulness in other directions. It is not a depreciation of the work which they are doing if we deplore their failure in another branch of work which they might be doing. From what I know of these institutions, and from information furnished by very good authorities, I am satisfied that in some directions, and more especially in connexion with engineering and trade subjects and handicrafts-in all of which the artisan is an important element-they are doing a certain amount of good to the various industries concerned. But the danger for us is the general tendency in this country to ram the whole scheme of education into one mould, utterly regardless of the fact that the requiremenț of, let us say, an engineer are quite different from those 
of a chemist. It is for this among other reasons that our subject has suffered both in its scientific and industrial aspects, because the time and energy of the teachers of chemistry in these institutions are so largely frittered away in what might be called inconsequential labour on behalf of a class of student quite unprepared by previous training for assimilating the principles of our science and for the most part unable to give sufficient time to the subject to acquire any real working knowledge of it.

It must be remembered also that most of the work of these institutions is carried on in the form of evening classes; in some few of them day classes are also conducted, the day and night classes being taught by the same staff. It is no matter for wonderment that with such burdens imposed upon the teaching staffs the new departure in technical education has failed to create centres of chemical research. The failure is not due to the want of ability on the part of the teachers; there are, as we know, many men of proved competency on their staffs, and many more would be attracted were the conditions made more favourable. The defect is in the constitution of the governing bodies, which bodies largely reflect the popular attitude towards research and on which our subject is, for the most part, altogether unrepresented or else swamped by the predominating influence of those with whom the handicraft view of education is paramount.

There is another factor to be added to those which are acting detrimentally towards the cause of research in these institutions, and that is the want of sufficient endowment. I am afraid that it is characteristic of our countrymen to neglect the most important interests until they are forcibly awakened to their danger and then to try and make up for past neglect by rushing precipitately into the first plausible scheme that is presented. There is no doubt that the new educational development suffered much at the outset from this characteristic mode of procedure. The wrong kind of person was often allowed to frame the educational policy; the financial strength was exhausted in buildings and equipment, and the efficiency of the staff given only secondary consideration. We, of course, know that success in such educational work depends entirely upon the individual teacher-that the best mode of creating a school of chemistry, or any other subject, is to follow the advice of the late Sir William Flower with regard to the establishment of a museum: "First find a curator and let him build his museum around him." Had this principle been more generally adopted the new institutions might by this time have been playing a really important part in the development of chemical science and chemical industry. As matters are, inadequate provision for maintenance 
having been made, the general standard of educational work is lowered in order that the grant-earning requirements of some examining board may be met, and as a result the establishments have to be run as purely business concerns. This influence makes itself folt in many ways detrimental to our cause. In the first place, there is introduced that most baneful system of teaching the subjects in "classes" so that a syllabus qualifying for some particular examination may be gone through in a certain time. It is quite unnecessary to point out here that individual originality or the spirit of research can never exist in such an atmosphere. And the most serious aspect of the case is that, not only is a subject taught in this way never really assimilated so as to become a living principle with the student, but, what is far worse, the teacher himself, however original and zealous at the outset, is bound, after running in this groove, sooner or later to undergo deterioration. That is one of the reasons why the polytechnic movement has produced such a very small effect upon chemical industry, and has been to all intents and purposes a failure so far as concerns the advancement of our science.

There are other minor evils acting as retarding influences with respect to our subject and arising from the same cause, namely, the necessity of conducting these newer institutions, more or less, as commercial establishments. The prevalence of the "business" spirit among the committees and governing bodies gives an exaggerated importance to what may be called the office staff-the registrars and clerks. The work of the office staff is capable of being appreciated by the average committeeman, while the work of the scientific staff is generally beyond his comprehension, excepting so far as it can be measured by financial gain to the institution. The principals of these institutions are, it is true, always men of scentific training, and, by the way, generally engineers or physicists; with the one exception of the Sir John Cass Technical Institute there is no chemist at the head of any of the London polytechnics. But the principals, however enlightened may be their individual views, are still answerable ultimately to their governing bodies, and that is equivalent to the statement that they are more or less subservient to the business interests of the institutions. Now, I am not decrying the business faculty as such; it is an essential qualification for the proper government of any educational establishment, and I am afraid that many of our scientific workers and teachers are very much lacking in that faculty. But that is no reason why the teaching staff should be, as is frequently the case, subordinated to the office staff. It is not sufficiently realised that men of business and administrative ability are by no means rarities while really 
good teachers of science are much scarcer, and men who combine both the qualifications of a good teacher with the inspiring zeal of an original investigator are rarest of all. Nbw if, as was professedly the case, the modern departure in technical education had for its object the improvement of the industries, then it is suffciently well known to us here that the future of our subject is with the men of the latter class, and the joint exertions of all the registrars and clerks, backed by the efforts of the most skilful chemical pedagogues who get through their syllabus within the session and earn the largest grants or score the highest percentage of successful "passes," will never raise the level of this country either in chemical science or chemical industry.

There is another practice which must be considered as injurious to our cause and which is familiar to all who have watched the progress of the technical education movement of late years, this also being the obvious result of insufficient endowment. I refer to that statistical standard by which the success of these institutions is chiefly if not absolutely judged. There is a tendency to measure the capabilities of the teachers by the number of students attending their courses, a-criterion which, from our point of view, is both fallacious and mischievous. The fact that certain industries, and especially those connected with electrical engineering, have so largely fed the classes of the newer institutions cannot be interpreted as indicating that the teachers of these subjects are better qualified than the teachers of chemical subjects. The skilled artisans who derive benefit from theoretical instruction in subjects with which their everyday occupations make them practically familiar, are very much more numerous than the corresponding class engaged in chemical occupations. Perhaps it would be nearer the truth to say that in the latter there is no class of students exactly comparable with those representing engineering occupations in the polytechnics. At any rate, no comparison of relative merits of teachers, or of importance of subjects based on purely numerical statements, is of real value, and where such a standard is insisted upon the effect is obvious-the teacher is forced to compete with subjects which are really not comparable and so aims at numbers; he fills his classes with students whose numbers are accounted for not by zeal for becoming proficient as chemists, but by the promise which the subject offers as a means of scoring examinational success. Here again is there degradation of teacher and of subject, and the spirit of research is naturally stamped out under the treatment. As a matter of pure political economy, if it is desired to benefit the chemical industries of this country through the polytechnics, it would be better to make a 
selection from the chemical staffs of these institutions, to relieve these men from all teaching, and to subsidise them to the same extent for carrying on original work. I venture to think that both science and industry would gain by the change.

It is sometimes stated that it was never contemplated that research should be carried on in these institutions-that this was the duty of the higher educational establishments. So it is the duty of the higher educational establishments, but the very fact that these are enabled to discharge their duty in a most imperfect way should have stimulated the newer institutions to make every effort to redeem our credit by making adequate provision for research. I will not venture to intrude my opinions concerning the vitalising influence of research upon other scientific subjects, but with regard to our own I have not the least hesitation in declaring the belief that a school of chemistry which is not also a centre of research is bound to degenerate and to become a mere cramming establishment not worth the cost of the maintenance. It is easy enough to follow the actual course of the degeneration process in such an institution. The teacher, who may be a man of real ability and who has entered with the hope of finding time and opportunities for research, finds himself, sooner or later, in the position of a chemical schoolmaster. The predominance of the business influence in the institution not only leads, as $I$ have already indicated, to the lowering of the level of the instruction and to his own consequent degeneration, but he is, as a further consequence, so overweighted with business and administrative work that these, superadded to his teaching duties, leave him neither time nor energy for original work. The spirit of research within him is strangled by officialism and his teaching faculties deadened by the monotonous toil of the annually recurring drudgery of routine teaching. He has not even time to educate himself by keeping in touch with the progress of his subject, and one of two things must happen; if he remains at his work his research faculty is lost to the country and his teaching becomes less and less efficient as he falls more and more behind the actual state of knowledge-he undergoes submergence. Or, as the other alternative, he abandons the career at the first opportunity and is replaced by another teacher who undergoes the same process of submergence, or, what is more generally the case, the good teacher is replaced by an inferior one because the reputation of the institution as a centre of research is not such as to attract the highest class of teacher.

The scale of remuneration also does not enable these institutions to command the services of the best teachers, although I do not 
think that this is the chief deterrent cause, as there are numbers of young chemists of first-rate training and ability who would be quite willing to devote their time at the outset of their career to acquiring teaching experience in these establishments, even at some personal sacrifice, if facilities for research were given. In the present state of affairs one can only marvel at the fact that so many men of ability can be found willing to take service in these newer institutions, the more especially as, apart from the absurdly inadequate remuneration often given to the chiefs of the chemical departments, the payment of the subordinate members of the staff is generally on a scale which is nothing short of a scandal to the wealthiest of European nations. Considering the long course of training necessary to produce a competent teacher or demonstrator, and in view of the actual amount of work expected from these men who, by virtue of their attainments and position, are compelled to live up to a standard of high respectability, it seems almost incredible that the average scale of remuneration should not exceed the wages earned by an artisan and is often below that standard. It is instructive from this point of view to note the advertisements which appear when these posts have to be filled and to compare the qualifications required, the duties expected, and the salaries offered. This state of things is, unfortunately, not confined to the newer institutions, and an inquiry into the salaries paid to assistants and demonstrators throughout the country will show that in many of the older educational establishments there is the same inadequacy of payment. The practical result from our point of view is again the crippling of the research faculty; the chiefs are inadequately supported, and the subordinates have to work overtime as examiners, or in some other capacity, in order to make a "living wage." It is needless to say that under such conditions there is wholesale destruction of research talent going on to the ultimate detriment of our country.

I have thought it desirable to deal at some length with the shortcomings of the newer institutions, because the older educational centres have been so frequently castigated without effect, that there should be some hope of bringing about an improvement in the position of chemical research in establishments which, in principle at least, profess to meet the latest educational requirements in applied science. It will be remembered that at the outset of the movement the late Prof. Huxley encouraged the foundation of these newer institutions by describing them as "capacitycatching" appliances-machines for sifting out the national talent and passing it on to higher work. I do not for a moment imagine that our great leader ever contemplated that capacity would be 
caught by these appliances in order to strangle it. Yet that is virtually what is going on to a very large extent under the enforced conditions of teaching our subject to which I have called attention. According to the "Official List of Appointments" published by the Institute of Chemistry last year there are on the staffs of the London and suburban Polytechnics about fifty-four trained chemists. To these may be added 237 engaged in teaching in similar institutions in provincial centres throughout the United Kingdom. In one respect the hopes of those who expected great opportunities for chemists from the new departure in technical education have been realised. At the present time there are in this country in round numbers some 290 posts available for teachers of chemistry, which posts have actually been created by the latest movement in technical education. If now we ask whether the output of original work from these 130 centres is representative of the productive power of the 290 teachers, there can, I think, be only one answer, and that an emphatic negative. An examination of the lists of teachers in these centres shows that only about twelve out of the total number are carrying on research, and most of these in a desultory way. It is evident that there is justification for my complaint that there is this submergence of creative faculty going on all over the country; the nets have been spread and the capacity has been caught, but so far with comparatively little effect upon the development of new schools of chemical research.

The next question, whether the influence of the newer institutions upon chemical industry has realised our expectations, is intimately connected with the educational side of the subject with which I have been dealing. No institution which runs classes in chemistry for examinational purposes only and which affords no opportunities for research to its teachers can be expected to produce any serious effect upon the industry, and it is not surprising that the manufacturers should look with suspicion upon such products of modern technical education. It is extremely difficult to obtain information as to the kind of chemical student attending these newer institutions in various parts of the country. The majority

I should say by far the larger majority-are preparing for a certificate or a degree, and not for the purpose of becoming working chemists. Speaking from my own experience, I can say with regard to evening students in institutions which are not fettered by any examinational requirements, that a certain amount of good has been done in isolated cases. I could name foremen and managers in chemical works whose promotion has been the result of their attendance at evening classes, and I could name teachers who have 
become converted from pure pedagogues into really efficient teachers by attending the practical laboratory courses. But institutions of this type are, it must be remembered, in a very small minority, so small that they may be left out of consideration in dealing broadly with the relationship between modern technical education and chemical industry. The question really before us is whether the small amount of good effected by the newer institutions as a whole is not achieved at too great a cost in the way of individual originality - whether it is worth sapping the vitality of two or three hundred teachers of chemistry so as to leave those of them who possess the research faculty without time or energy for such work in order that a few foremen here and there may be improved in position. So far as chemical science is concerned we can only deplore this squandering of our most precious asset; so far as concerns chemical industry I venture to think the result is too trifling to be worthy of serious consideration.

It is not easy to get accurate information as to the actual numbers of chemists employed in factories in this country. In the first place, many of our manufacturers dignify with the name of "chemist" any human testing machine in their employment, and there is no doubt that many men whose daily occupation does not go beyond the valuation of a few staple products or raw materials are described as chemists. In 1902 a Committee of the British Association published a statistical report on this subject, in which are set forth the numbers of "chemists" engaged in the different branches of chemical industry and the kind of training which they had received (Brit. Assoc. Report, Belfast, 1902, p. 97). According to the returns furnished to this Committee the total number of chemists in those factories which supplied information is about 500, and Sir James Dewar, in his Presidential Address for that year (loc. cit., p. 15), on the authority of Prof. Henderson, gives as a liberal estimate a total of about 1,500. Whatever the actual number may be, it appears from the report that evening classes, together with analysts' and works' laboratories, supplied only a total of eighty-five, so I think there is justification for the contention that the effect of the newer institutions upon chemical industry is quite insignificant.

The consideration of the question of the position of factories as centres of research is, as I have previously stated, intimately bound up with the educational side of the subject because we have to deal now with the educational establishments which are supplying the chemists for our factories. We must really include also among these the foreign Universities and Technical Schools, because many of the works' chemists employed here were educated 
abroad. It is not my intention now, nor is it essential to the point under consideration, to institute a comparison between the merits of the English and foreign-trained chemist. We are, I am sure, all agreed that the only men likely to be of real use in chemical industry are those who, starting from a sound, general education, have been through a systematic and organised course extending over at least three years and followed, if possible, by some experience in research. For those who are to become leaders in the industry the research training is, I should say, absolutely indispensable. Thus it is only institutions in which this kind of work is going on that need be taken into consideration, and it is because so few of the newer institutions here are doing this kind of work that they have, as I have already pointed out, more or less failed in that object for which they were specifically founded. Now our Universities do not profess to cater especially for the training of industrial chemists, although a few of their graduates have found careers in factories. The later development of departments of applied science at some of our Universities, such as Leeds and Birmingham, is certainly a move in the right direction and one from which great good to particular industries may be expected to follow. It would be impossible for me in the time at my disposal to attempt to deal with the large and important question of the kind of training which the chemical student should undergo, or with the question of the suitability of this, that, or the other curriculum. The bare fact that about forty out of the total number of chemists employed in this country were, according to the report already quoted, educated in foreign Universities or Technical Schools, shows that there must be some superiority in the foreign system. The numbers of English, and I may add American, students in the foreign Universities bear testimony to the same effect.

The feeders of the chemical factories are thus the Universities and Technical Schools, British and foreign, and the question before us as the custodians of research is whether the absorption of the chemical talent from these sources by the factories is justified from the industrial point of view-whether these products of modern training, having entered into such careers, are being used to the best advantage. In other words is that wastage of original faculty which, as I have endeavoured to show, is going on in the educational institutions going on also in the factories? Now, I have already pointed out that any original work done in a factory for trade purposes is no concern of ours, and it will be readily understood that great difficulty would be encountered in any attempt to get accurate information on this point. But in view 
of the circumstance that so many teachers of our subject are devoting their lives to this very work, that we are ever on the alert for that most precious research faculty in order to train it and to add it to our national assets, we are, I believe, justified in asking what becomes of these men when they enter the ranks of industrial chemists? Whether the total number of chemists employed in our factories is what it should be is a point for the manufacturers themselves to consider. Even the extreme estimate of 1,500 does not seem a very large chemical staff for the whole of the factories of Great Britain. In the German colour industry alone, according to information supplied to us seven years ago as Jurors for the Paris International Exhibition, five of the great factories were employing 557 chemists-real scientific chemists and not mere testing machines such as are dignified with the name of chemist in many of our factories.

From my own experience as head of the chemical department of a Technical College, and with some knowledge of the requirements of chemical industry, I can state that the newer technical education when conducted in the form of organised courses of day instruction extending over several years has enabled us, according to Huxley's metaphor, to capture a large amount of chemical capacity. I have no doubt that others attached to similar institutions can supplement and extend my own experience. During twenty-two years' connexion with the Finsbury Technical College I estimate that in round numbers from 300 to 400 trained students have been made over to the chemical world. Add to those the students from other institutions doing similar work and it will be seen that the supply of chemical talent available for science and for industry is very large. In giving these figures it must be remembered that they refer to bona-fide chemical students, young men who have gone through the course with the definite object of making chemistry either a profession or a trade. Now of the total output of trained chemists from the various institutions a fair proportion-a number quite equal to the average in other countries -are possessed of the research faculty. We have seen what becomes of this when such men throw in their lot with the educational establishments. Are not we, the teachers, justified in asking whether the prospects of developing this faculty in our factories are such as might be reasonably expected from the known requirements of chemical industry?

In answer to this question I am afraid we must come to the conclusion that here also there is an enormous submergence of research talent going on. It is true that the position is improving-that some of our more enlightened manufacturers have realised the 
value of such men, and by taking advantage of their faculties have improved their various industries. But these cases are as yet exceptional, and the ideal will never be reached until the research laboratory becomes a recognised and well-staffed department in every chemical factory. Do our factories possess departments which can honestly be described as centres of research in the sense, say, of the research laboratories of the German colour factories? I am afraid not; indeed, I know of scores of young men of great promise and ability who have been swallowed up by the factories and gradually degraded, in the chemical sense, into mere machines carrying out routine work which really required no elaborate chemical education for its effective performance. There is, of course, no satisfactory means of measuring the influence of the newer education upon the chemical industries of this country, and we can only speak from individual experience concerning the careers of our own students. It is upon this experience that $I$ base the conclusion that our country is wasting its resources in a most reckless way so far as concerns the chemical industries. There is an enormous amount of talent available if our manufacturers would only utilise it in the right way. It has frequently been pointed out how, on the Continent and in America, the educational establishments and the industries are brought into relationship by the co-operation between the manufacturers and the teachers. Only last week in his lecture at the Royal Institution Prof. Lunge again drew attention to this point in forcible terms. Here, so far as chemical industry is concerned, such co-operation is practically unknown, and, as a consequence, there exists more or less distrust where there should be confidence, and both the educational and the industrial sides of our subject are crippled. This is perhaps the most powerful influence at work in this country in checking that development which follows normally from co-operation between the representatives of science and of industry.

We cannot profess, nor is it possible for any educational establishment, British or foreign, to undertake to supply men with an expert knowledge of any particular branch of manufacture. We can only say when asked for such, "We can supply you with men of general knowledge of principles and possessed of originality and resourcefulness; take them into your factories, put them into research laboratories where they have a free hand, make them acquainted with the problems awaiting solution in your industry, and do not be too impatient for immediate results; in the long run such men will justify their appointments." That this ideal utilisation of the national chemical faculty is not going on to the 
extent that it ought appears to me to be shown in two ways. I may be possibly opening the door for controversy here, and so it is better to state at once that $I$ am not raising the vexed question of the imperfections of our Patent Laws. But I do not think it can be reasonably questioned that in the present state of chemical literature the patent list is, on the whole, a very fair measure of the research activity in the factories, and from that point of view it is quite unnecessary to do more than invite a comparison between the discoveries in the way of chemical products and processes emanating respectively from the British and foreign factories. The other criterion of research activity is furnished by the Society of Chemical Industry-an excellent organisation of which we are all justly proud. That Society does for applied chemistry what we are doing for chemical science; it provides an arena for the announcement and discussion of new discoveries in industrial chemistry, and it gives publicity to the results in the pages of its Journal. Now it is no disparagement to the work of that Society to say that the contributions to its Journal representing the total results of research conducted in the factories of this country are exceedingly meagre. That, of course, is no fault of the Society as a Society, but the paucity of original communications may be taken in conjunction with the revelations of the patent lists as a justification of the complaint that in the factories, as in the educational establishments, there is going on this same wastage of the research faculty.

Checks to the Wastage of the Research Faculty; Research Funds and Scholarships.

Turning now from the consideration of the various deterrent influences, we may in the next place deal with such counteracting agencies as are available in this country. It is clear, from our point of view, that any means by which the research faculty, having once been captured, can be given free scope for development must be a distinct gain to our cause. All who have had to do with the training of chemical students must in the course of their experience have come across young men of exceptional talent as original workers. Fortunately for the intellectual vigour of the nation this faculty is not a class distinction, and is to be met with occasionally in all ranks. Possibly the lower ranks have the advantage, but the actual facts can only be arrived at by Galtonian methods. We are concerned more particularly with the utilisation of this faculty for the promotion of our science and with the maintenance of the principle that the submergence of this 
faculty means so much dead loss to the national resources. Now it unfortunately happens that many of the men thus gifted come from stations in life which render it imperative that they should proceed at once from the college to some bread-winning occupation. A few may perhaps be lucky enough to find appointments in which there is scope for the development of their faculties, but I am afraid the majority do not; they undergo that process of extinction as original workers which I have already dealt with. I could point to large numbers of cases illustrative of this most deplorable waste of productive energy, and other teachers could, no doubt, do the same. One of the most valuable counteracting agencies, and one the importance of which, from our standpoint, cannot be overestimated, is that system of awarding research scholarships to men of proved ability so as to enable them to carry on original work after finishing their college training. The value of this most rational method of endowing research is due mainly to the fact that the right men are captured in the right way; they are not, as it were, squirted promiscuously out of an examination mould, but they are selected by the teachers who have had them under observation during the whole course of their training and who know their real as distinguished from their examinational capabilities.

This method of promoting science and at the same time giving the crowning touch to the scientific education of the best products of our educational establishments is of such national importance that we should fail in our duty did we not place upon record our high appreciation of those agencies which are working in this direction. Unfortunately they are few. The amount of capital required for the adequate endowment of such scholarships is necessarily large, and the public spirit of our countrymen very rarely expends itself in this direction. But I desire especially to name among others the scholarships given by the Royal Commissioners of the 1851 Exhibition, the Salters' Company's Research Scholarships, the Schunck Research Fellowships, and the Carnegie Research Scholarships, all of which are doing excellent service in the cause of chemical research in this country, as may be seen from the pages of our publications. Of the value of these endowments there can be no question, and with respect to the Science Scholarships of the 1851 Exhibition I can speak from personal experience, having for many years been one of the examiners of the reports presented by the scholars. These last scholarships are not limited to chemical subjects, but our science claims, on the whole, the largest number of scholarship holders. But, although we should probably be unanimous in our estimate of the importance of such endowments as these, there is another aspect of the case to which, I think, it VOL. XCI. 
right to call attention, if only for the opportunity it affords for answering certain objections to the specialisation of work rendered necessary by devotion to research.

It has sometimes been urged by educational authorities whose opinions are entitled to serious consideration, that it is unfair to students at the close of their general education to place temptation in their way by furnishing means whereby they are induced to devote perhaps some years to specialised research of no breadwinning value in their ultimate career. It is not difficult to answer this objection, although there may conceivably be conscientious teachers who on this ground would discourage post-graduate research work. In the first place, if the educational value of research be admitted, as it assuredly will be, it must necessarily be limited to some special field, and if, as is so generally the case, the student on the completion of his curriculum has no definite views as to his future line of work, it is obviously impossible to specialise his researches with reference to his prospective career. We can only proceed on the general principle that research in itself is of the highest disciplinary value in whatever career the student may ultimately adopt as a chemist - whether he becomes a teacher or a technologist; it being, of course, understood that no specialisation is permitted until the general scientific education has been completed on a broad and sound basis.

The question is whether this principle is a sound one, and as a matter of experience I have no hesitation in answering that question in the affirmative. The faculties called forth by research work, although for the time being concentrated on one particular problem, are just those which are essential for success in any branch of our subject. The nature of the particular line of investigation by which those faculties have been trained is in reality a subordinate point, subject entirely to personal conditions; that is to the special nature of the work with which the professor or teacher is associated. In cases where a choice of centre is possible the research student would naturally go to that institution where the work was in a field in which he was most interested or towards which he was attracted as affording a good preparation for his future career. But even where no choice of centre is possible, and where an opportunity for continuing research work in his own college after passing through the general curriculum is furnished by agencies such as those to which $I$ have referred, the value of the student is enormously enhanced by the experience. The man and the subject are both gainers, and from my own knowledge of the careers of students who have availed themselves of such scholarships I have no hesitation in expressing the view that it is 
the duty of all teachers who are afforded the opportunity to encourage in every way the utilisation of these endowments. It is the teachers who are the real capacity catchers; it is their duty out of loyalty to our science and in the best interest of those who are taking to chemistry as a career to see that these available sources of productiveness are made the most of, and I again emphasise the indebtedness of the country to the founders of these scholarships.

The other agency working against the stream of adverse influences is to be found in the various funds from which grants are made to individual workers for the prosecution of particular researches. There are three such funds available for the promotion of chemical research, the Government Grant Fund of the Royal Society, the grants distributed annually by the British Association, and the income derived from our own Research Fund. Of these the two former have to be distributed over every branch of science, and chemistry takes its chance with other subjects. The total amount available for chemical research is not very large, and all who have served on the committees of any of these funds know very well that the amount applied for is generally much in excess of the sum available for distribution. The main difficulty of administration is, in fact, the equitable pruning of the various applications.

With regard to the results obtained through the Research Fund of this Society, the present occasion is in every way opportune for calling attention to our achievements and to our needs. The history of this fund is fully given in our Jubilee volume, published in 1891, and it is, therefore, unnecessary to recapitulate that history now. The income derived from this fund has bitherto enabled us to distribute annually a sum of about $£ 220-a$ very modest amount considering the number of claims and the activity of our workers. Of the value of the assistance thus given we are, of course, all thoroughly aware here, but it may not be generally realised by the outer public what an enormous amount of good work is being promoted by the judicious administration of this very modest income. In order to get at the actual facts, Mr. Carr has been so good as to prepare a table covering the eight years from 1898 to 1905 inclusive, and setting forth for each year the sum granted, the number of grantees, the total number of papers published by the grantees in our Journal or elsewhere, and other particulars which will be found in the table itself.* From this it appears that 151 grantees during that period published 203 papers, thirteen failed to publish, ten have not yet published, and

* See Appendix B, p. 659. 
eighteen grants are still in the hands of the grantees. The total amount granted was $£ 1,770$, so that for this expenditure we have actually given to our science 203 papers, and more may be expected from those who still have grants in hand or who have not yet published their results. The figures as they stand, and even if nothing further is achieved, show that the grants average from $£ 8$ to $£ 9$ per paper, and, as we all know, each paper represents the results of at least one and frequently of several years' work. Moreover, in many cases the sums allotted are of more than subsidiary assistance; some of our workers are practically dependent upon these grants for procuring the necessary and often costly materials required for their researches, and without such support would be unable to carry on their work. It is not going too far to say that there are no funds giving such substantial returns for so small an expenditure as these Research Funds, and their importance as aids to the advancement of knowledge cannot be overestimated.

I have thought it desirable to set forth the results accomplished by our Research Fund on this occasion, because several points and considerations connected with this branch of our work have arisen during the past year. It will be remembered that one of the objects which the promoters of the Coal-Tar Colour Jubilee celebration embodied in their scheme was the establishment of a Research Fund to be administered by this Society in association with the name of the founder of the industry, Sir William Perkin. As the causes acting detrimentally to the progress of research in this country have been so fully considered in this address, I cannot refrain from calling attention to a very remarkable attack upon that part of the scheme which appeared in one of the technical journals.* That a discordant note should have been sounded by a countryman of Perkin's at a time when foreign nations were co-operating loyally with us for the realisation of the objects set forth by the promoters will appear almost incredible to posterity when the proceedings of that great international gathering have passed into the domain of history. The answer to that attack was, of course, given in the theatre of the Royal Institution last July in terms which form a very striking comment upon the views expressed by the writer of the letter in question, and as a further practical refutation $I$ am glad to be able to announce that a net sum of about $£ 2,700$ will be added to our capacity-catching resources in the form of a "Perkin Research Fund," that sum having been raised by international subscription in honour of our distinguished past-President. It was also, as you are aware, my

\footnotetext{
* Journal of Gas Lighting, etc., June 5th, 1906, p. 648.
} 
pleasing duty last month to announce a further contribution of $£ 1,000$ from the Goldsmiths' Company for the promotion, through our Society, of research in Inorganic and Metallurgical Chemistry.

I will venture in conclusion to dwell upon another aspect of the work of our Research Fund which must, I am afraid, in the present state of affairs be regarded as purely hypothetical. At some future period the hypothesis might possibly become practically verifiedit is entirely a question of means, and, unfortunately, of very large means; but I am most anxious to bequeath to my successors in this chair at least the tradition of the desirability of realising the views which I have long held on this subject, and so I take advantage of this last opportunity of addressing the Society in the capacity of President to formulate these views with some emphasis.

Let us consider, in the first place, the actual resources at our disposal for the promotion of research. With the additional capital by which our fund has been increased the total income available for grants will be about $£ 330$ per annum. In view of the demands upon that income it is obvious that even now we are possessed of but very limited means, and that the Research Fund Committee will still be compelled, as has hitherto been the practice, to allot the grants for the purchase of materials or special apparatus. This mode of allotment has been recognised as a principle by the Committee for many years, and in view of our slender resources no other course is possible. Administered on this principle the fund has been, as I have already stated, of enormous value in the past, and it is to me a matter of the greatest satisfaction in retiring from the Presidency to know that during my period of office the substantial increase of our resources will enable us to extend the sphere of usefulness of the fund in the future. But, in addition to the promotion of research by the means indicated, there is another, and, according to my view, an equally valuable method for assisting our workers in the prosecution of their researches, and that is the allotment of personal grants to enable the grantees to secure skilled assistance-to purchase, in fact, the services of human material as well as chemicals and apparatus. It is only. want of sufficient income that has hitherto debarred the use of our fund in this way; the Government Grants administered by the Royal Society are, as you are aware, allotted to applicants in certain cases for such personal assistance, and the great desideratum of our Research Fund is a sufficient augmentation of capital to enable us to do the same kind of work.

I am so confident that an extension of our means towards this end would be productive of a most notable increase, both in the 
quantity and quality of the chemical research done in this country that I have no hesitation in placing upon record the opinion that the next step taken in the forward policy of the Chemical Society ought to be in this direction. To do much good in the way of making personal grants we should, of course, require to capitalise a very large sum; we want an income of thousands instead of hundreds, and I confess that I see no immediate prospect of realising this dream. But there can be no doubt that for those who have the interests of our science at heart there could be no better method of subsidising research. In strengthening the hands of workers by such means the efficiency of the capacity-catching machinery would be increased in the best possible way, both for the subject and for the individual. The active worker is the best of all possible selecting agents; the assistant chosen by him could be depended upon as being a man of proved competency, and possibly of his own training. The assistant so selected would benefit largely by his association with the active worker; he would rise in the scale of competency with increasing experience and might in his turn be expected to become an active centre of research. Supposing grants of this order were made possible to our Society, there would be added to the influences already referred to another power tending to check that dissipation of the research faculty which, as I have endeavoured to show, is going on to such a deplorable extent throughout the country.

The general conclusion which appears to be justified by this inquiry into the position and prospects of chemical research is, that the position here is by no means as satisfactory as we could wish-that much more might be done if the conditions were made more favourable for our active workers. In view of the actual achievements, accomplished in spite of the existing disabilities, it appears that the prospects for this country as a home of chemical research have been improving during the last decade with greater rapidity than at any previous period in the history of our Society. But it is also obvious that there is much work yet ahead of us before the environment in which our workers find themselves is properly cleared from obstructions. The remarks which I have offered on this occasion may possibly be of use in indicating the directions in which such impediments are to be found. 
Appendix A.-The Publications of the Chemical Societr, 1895-1906.

\begin{tabular}{|c|c|c|c|c|c|c|c|c|c|c|}
\hline \multicolumn{4}{|c|}{ Transactions. } & \multicolumn{2}{|c|}{ Abstracts I. } & \multicolumn{2}{|c|}{ Abstracts II. } & \multicolumn{3}{|c|}{ ProceEdings. } \\
\hline 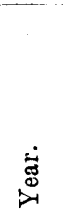 & 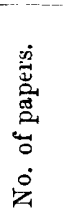 & 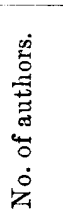 & 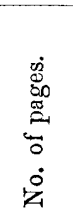 & 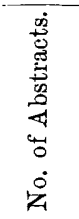 & 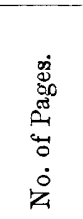 & 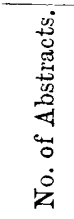 & 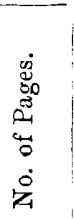 & 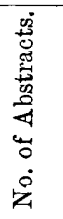 & 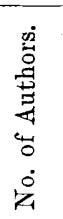 & 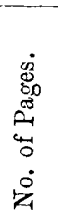 \\
\hline 1895 & 116 & 109 & 1082 & 1190 & 692 & 1292 & 544 & 157 & 132 & 241 \\
\hline 1896 & 117 & 108 & 1465 & 1201 & 716 & $\begin{array}{l}1298 \\
1638\end{array}$ & $\begin{array}{l}544 \\
684\end{array}$ & 174 & $\begin{array}{l}102 \\
141\end{array}$ & $\begin{array}{l}241 \\
251\end{array}$ \\
\hline 1897 & 114 & 109 & 1139 & 1049 & 648 & 1526 & 612 & 129 & 123 & 250 \\
\hline 1898 & 102 & 100 & 996 & 1187 & 720 & 1639 & 660 & 151 & 121 & 252 \\
\hline 1899 & 120 & 110 & 1166 & 1477 & 968 & 2140 & 828 & 172 & 148 & 244 \\
\hline 1900 & 127 & 117 & 1160 & 1355 & 712 & 2403 & 780 & 180 & 152 & 231 \\
\hline 1901 & 146 & 139 & 1340 & 1530 & 784 & 2224 & 712 & 180 & 161 & 266 \\
\hline 1902 & 160 & 145 & 1575 & 1632 & 852 & 2222 & 712 & 194 & 165 & 255 \\
\hline 1903 & 142 & 126 & 1460 & 1650 & 872 & 2232 & 768 & 181 & 157 & 292 \\
\hline 1904 & 175 & 168 & 1714 & 1968 & 1072 & 2649 & 848 & 215 & 175 & 252 \\
\hline 1905 & 184 & 168 & 1818 & 1727 & 956 & 2629 & 872 & 233 & 221 & 312 \\
\hline 1906 & 186 & 183 & 1890 & 1745 & 1000 & 2796 & 912 & 236 & 215 & 326 \\
\hline
\end{tabular}

Appendix B. - The Work of the Research Funl), 1898-1905.

\begin{tabular}{|c|c|c|c|c|c|c|c|c|c|c|}
\hline 急 & 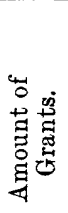 & 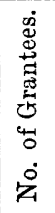 & 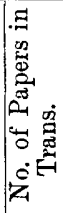 & 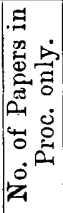 & & $\begin{array}{l}\text { No. of Papers published } \\
\text { elsewhere than in } \\
\text { Trans. Chem. Soc. }\end{array}$ & 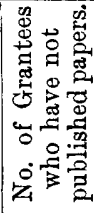 & 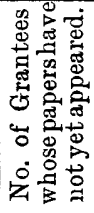 & 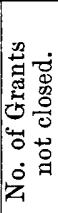 & 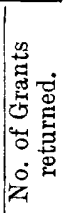 \\
\hline 1898 & $\begin{array}{c}f \\
245\end{array}$ & 22 & 24 & 2 & & & 3 & & & \\
\hline 1899 & 192 & 13 & 23 & & & & 2 & & & 2 \\
\hline 19 & 170 & 11 & 14 & & & & 1 & & & \\
\hline 1901 & 250 & 21 & 24 & 1 & & & 1 & & & \\
\hline 1902 & 230 & 17 & 35 & 1 & & & 2 & & 6 & 1 \\
\hline 19 & 232 & 19 & 17 & 3 & 2 & Proc. R. S. & 1 & 1 & 2 & 4 \\
\hline 19 & 215 & 21 & 21 & 1 & 1 . & Ceramic Society. & 1 & 2 & 5 & 1 \\
\hline 1905 & 236 & 27 & 30 & 3 & 1 & "Berichte." & 2 & 7 & 5 & 2 \\
\hline Total. & 1770 & 151 & 188 & 11 & 4 & & 13 & 10 & 18 & 10 \\
\hline
\end{tabular}

